\title{
Clinical Characteristics and Factors Associated with Disease Progression of Mild to Moderate COVID-19 Patients in a Makeshift (Fangcang) Hospital: A Retrospective Cohort Study
}

$$
\begin{aligned}
& \text { Jia Liu',* } \\
& \text { Jun-Fei Zhang }{ }^{2, *} \\
& \text { Han-Ning Ma }{ }^{2} \\
& \text { Ke Feng } \\
& \text { Zhong-Wei Chen } \\
& \text { Li-Shan Yang } \mathbb{D}^{2} \\
& \text { Bin Mei } \\
& \text { Jun-Jian Zhang }
\end{aligned}
$$

'Medical Experimental Center, General Hospital of Ningxia Medical University, Yinchuan, Ningxia, 750000, People's Republic of China; ${ }^{2}$ Department of Emergency Medical, General Hospital of Ningxia Medical University, Yinchuan, Ningxia, 750000, People's Republic of China; ${ }^{3}$ Department of Social Medical Development, Zhongnan Hospital of Wuhan University, Wuhan, Hubei, 43007I, People's Republic of China; ${ }^{4}$ Department of Neurology, Zhongnan Hospital of Wuhan University, Wuhan, Hubei, 43007I, People's Republic of China

*These authors contributed equally to this work

\begin{abstract}
Objective: Information regarding the epidemiology and clinical features of mild to moderate patients caused by COVID-19 in Fangcang Hospital is scarce. Through a retrospective cohort study, the clinical characteristics of COVID-19 patients in Dongxihu Fangcang shelter hospitals were analyzed, and the factors that affected the disease progression of COVID-19 patients were explored.

Methods: The clinical characteristics of 714 patients with COVID-19 were retrospectively analyzed at Dongxihu Fangcang Hospital between February 7 and March 8, 2020. We described the clinical characteristics and distribution of discharge or transfer times for each patient. According to the disease progression of COVID-19 patients, we divided all patients into Non-Deteriorated group and Deteriorated group. Furthermore, binary logistic regression was used for a single outcome and multiple response variables.

Results: We treated 789 patients with mild and moderate COVID-19, of which 714 were included in this study, which included 326 (45.66\%) deteriorated patients and 388 (54.34\%) non-deteriorated patients. The mean age of the study population was $48.16 \pm 12.44$ years. Of all patients, $319(44.7 \%)$ were men and $395(55.3 \%)$ were women. The average length of the patient's stay was $16.08 \pm 5.13$ days. The most common clinical feature on admission was fever (593 of $714,83.05 \%)$. It is worth noting that $80(11.20 \%)$ of the 714 patients were asymptomatic from exposure to admission. Multivariate logistic regression analysis showed that gender, age, diabetes, respiratory system disease, fever, dyspnea, and nasal congestion were risk factors associated with deterioration in cases with COVID-19 patients, and asymptomatic (OR: $0.058 ; 95 \%$ CI: $0.022-0.155 ; P<0.001)$ was the protective factor for deterioration of COVID-19 patients.
\end{abstract}

Conclusion: Accompanied by chronic diseases, old age, fever, nasal congestion, and dyspnea were factors that influenced the aggravation of COVID-19 patients, and more attention and treatment should be given to these patients.

Keywords: clinical characteristics, mild to moderate, makeshift (fangcang) hospital, influence factors

\section{Introduction}

On December 8, 2019, it was confirmed that several patients with pneumonia caused by unknown causes were infected with the new coronavirus, which has not been detected in humans or animals before. ${ }^{1,2}$ On February 11, 2020, the WHO named this novel virus "COVID-19" (Coronavirus disease 2019). Since then, the
Correspondence: Zhong-Wei Chen;

Li-Shan Yang

Email 13995390007@I63.com;

nyfyyls@।26.com 
WHO emergency committee has declared COVID-19 as a global health emergency with more than 200 countries reporting COVID-19 cases. Hundreds of thousands of new cases each day are still being reported as of January 20, $2021,{ }^{3}$ and without a therapeutic vaccine or specific antiviral drugs, early detection and isolation became essential. $^{2}$

From the perspective of treating patients and controlling the source of infection, a new model has emerged: Fangcang Hospital, which mainly treats non-critical patients with positive COVID-19 RT-PCR tests. ${ }^{2,4}$ As of February 19, 2020, 13 large public places in Wuhan, Hubei Province have been converted into shelter hospitals for patients of COVID-19 with mild symptoms. ${ }^{2,5}$ We were mainly responsible for the treatment of patients with mild and asymptomatic COVID-19 in Dongxihu Fangcang Hospital.

The infection is highly contagious and can spread from person to person, including among family members. ${ }^{6,7}$ However, the clinical presentation of COVID-19 patients ranged from asymptomatic to severe acute respiratory syndrome. ${ }^{7}$ Therefore, there is currently no specific treatment for COVID-19. ${ }^{6,7}$ Effective treatment of non-critically ill patients is an important means to prevent non-critically ill patients from turning into critically ill patients or even death. It is conducive to reversing the overloaded situation of hospitals and preventing the spread of the epidemic on a large scale. $^{2}$

In this study, we retrospectively analyzed the clinical characteristics of patients with mild to moderate COVID19 in Fangcang hospitals, and explored the factors affecting the course of the disease. Develop individualized preventive treatment methods in advance for high-risk patients, and take effective preventive measures as soon as possible to prevent the patient's condition from deteriorating or dying. ${ }^{3}$

\section{Methods}

\section{Study Design and Participants}

This study was a retrospective cohort study that included COVID-19 patients in Wuhan's Dongxihu Fangcang shelter hospital from February 7 to March 8, 2020. The Dongxihu Fangcang Hospital was reconstructed from the Wuhan Living Room Cultural Expo Center, which had the basic functions of medical care, logistics support, hospital beds and living quarters. Epidemiological data, basic information (gender, age, and comorbidities), symptoms (fever, chills, runny nose, nasal congestion, sore throat, cough, sputum, dyspnea, headache, myalgia, vomiting, diarrhea, and abdominal pain), RT-PCR analysis and Chest CT (CT) scan results were collected. ${ }^{4}$ The data were reviewed by a trained team of physicians. This study was approved by the Institutional Ethics Committee of the General Hospital of Ningxia Medical University (No. 2020-532). ${ }^{2}$ All procedures followed were in accordance with the ethical standards of the responsible committee on human experimentation (institutional and national) and with the Helsinki Declaration of 1975, as revised in 2008. Because of its retrospective and emergent nature and evaluation of the imaging and clinical data of the patients, the study involved no potential risk, and verbal informed consent was obtained from all patients to be included regarding publication of the case details, and our IRB approved the informed verbal consent process. $^{2}$ All COVID-19 patients who enrolled in this study were diagnosed according to the World Health Organization Interim Guidance. ${ }^{8}$ The clinical outcomes were monitored up to March 22, 2020, the final date of the follow-up.

\section{Inclusion, Exclusion, and Other Criteria}

Inclusion criteria: (1) All patients were diagnosed with COVID-19 by nucleic acid testing; (2) All patients were adults over 18 years of age; (3) All clinical data of the patients were complete; Exclusion criteria: (1) The patient refused to be included in the study; (2) Patients with mental illness or other conditions that affect their insight; (3) The hospital stay in Fangcang hospital is less than 24 hours; In addition, Table 1 shows the criteria for patient admission and exclusion in Fangcang hospital. All patients with COVID-19 were evaluated after treatment and were given further admission treatment or discharge observation according to their condition (Table 2 ). ${ }^{2}$ Therefore, according to the disease progression of COVID-19 patients, we divided all patients into non-deteriorated group and deteriorated group.

\section{Treatment and Outcomes}

The treatment was according to the latest guidelines for the diagnosis and treatment of pneumonitis caused by 2019-nCoV (trial sixth version) published by the Chinese government, and all patients received traditional Chinese medicine treatment. ${ }^{5}$ Most patients receive antiviral therapy, including oseltamivir ( $75 \mathrm{mg}$ orally every 12 hours) and lopinavir and ritonavir tablets $(500 \mathrm{mg}$ twice a day, 
Table I Admission and Exclusion Criteria in Fangcang Hospital

\begin{tabular}{|c|c|}
\hline Criteria & Specific Terms \\
\hline \multirow[t]{4}{*}{$\begin{array}{l}\text { Admission } \\
\text { criteria }\end{array}$} & $\begin{array}{l}\text { I. A positive result confirmed by standard COVID- } \\
\text { I9 RT-PCR test; }\end{array}$ \\
\hline & $\begin{array}{l}\text { 2. At rest, respiratory rate }<30 \text { and blood oxygen } \\
\text { saturation }>93 \% \text {; }\end{array}$ \\
\hline & 3. Age $\geq 18$ with self-care ability; \\
\hline & 4. A negative result for influenza virus $R T-P C R$ test. \\
\hline \multirow[t]{9}{*}{$\begin{array}{l}\text { Exclusion } \\
\text { criteria }\end{array}$} & $\begin{array}{l}\text { I. A negative result of standard COVID-19 RT-PCR } \\
\text { test; }\end{array}$ \\
\hline & $\begin{array}{l}\text { 2. At rest, respiratory rate } \geq 30 \text { or blood oxygen } \\
\text { saturation } \leq 93 \% \text {; }\end{array}$ \\
\hline & 3. Age $<18$ \\
\hline & 4. A positive result for influenza virus RT-PCR test; \\
\hline & $\begin{array}{l}\text { 5. Without selfcare ability and ability of daily life } \\
\text { activities; with severe acute and chronic } \\
\text { complications who require hospitalization; }\end{array}$ \\
\hline & 6. With mental disorder such as schizophrenia; \\
\hline & $\begin{array}{l}\text { 7. With serious psychological disorder such as } \\
\text { suicidal tendencies; }\end{array}$ \\
\hline & $\begin{array}{l}\text { 8. With other infectious diseases such as active } \\
\text { tuberculosis; }\end{array}$ \\
\hline & $\begin{array}{l}\text { 9. Expert assessment that it is not suitable for } \\
\text { admission to hospital; }\end{array}$ \\
\hline
\end{tabular}

orally). In most cases, patients also received broadspectrum antibiotic therapy. If the fever persists for more than 7 days, give quinolones and second-generation $\beta$ lactam drugs (oral). The patient received a single antibiotic or a combination of antibiotics.

\section{Statistical Analysis}

All data analysis is carried out with SPSS version 20.0 (SPSS Inc., Chicago, IL) software. Descriptive data statistics are appropriately represented using mean $\pm \mathrm{SD}$ and frequencies. When the data are normally distributed, independent group tests were used to compare the mean of continuous variables. The ratio of categorical variables was compared using $\chi^{2}$ test. All independent variables $(p<0.05)$ were used in a multivariable logistic regression analysis to identify factors associated with outcome variables. 95\% CI for odds ratio (OR) Hosmer-Lemeshow statistics and coefficient of deviation were used to test the goodness of fit of the model.
Table 2 Clinical Outcome Criteria for All COVID-19 Patients

\begin{tabular}{|c|c|}
\hline Outcome & Specific Terms \\
\hline \multirow[t]{3}{*}{ Deterioration* } & $\begin{array}{l}\text { I. Symptoms persisted or worsened for more than } \\
7 \text { days }\end{array}$ \\
\hline & $\begin{array}{l}\text { 2. At rest, respiratory rate } \geq 30 \text { or blood oxygen } \\
\text { saturation } \leq 93 \% \text {. }\end{array}$ \\
\hline & $\begin{array}{l}\text { 3. Pulmonary imaging showed that the lesions } \\
\text { progressed more than } 50 \% \text { within } 48 \text { hours. }\end{array}$ \\
\hline \multirow[t]{4}{*}{ Discharge } & $\begin{array}{l}\text { I. Temperature returned to normal for more than } \\
\text { three days }\end{array}$ \\
\hline & 2. Respiratory symptoms improved significantly; \\
\hline & $\begin{array}{l}\text { 3. Pulmonary imaging showed that acute exudative } \\
\text { lesions were significantly improved }\end{array}$ \\
\hline & $\begin{array}{l}\text { 4. With two consecutive negative results for RT- } \\
\text { PCR tests for sputum or nasopharynx swabs } \\
\text { samples (sampling time interval is at least I day). }\end{array}$ \\
\hline
\end{tabular}

Note: *Patients with any one of the following conditions were defined as deterioration of covid-19.

\section{Results}

\section{Treatment Procedure of Patients in Fangcang Hospital}

The flowchart of COVID-19 patients admitted to Fangcang shelter hospital is shown in Figure 1. In our Fangcang hospital, 789 patients with mild and asymptomatic COVID-19 were treated, of which 714 patients were enrolled in this study. There were 326 patients who needed to be transferred to hospitals for further treatment because the symptoms were not relieved or worsened. The remaining 388 COVID-19 patients were discharged after remission. Figure 2 shows the discharge or transfer time of each patient in the Fangcang shelter hospital.

\section{General Characteristics of Patients with COVID-19}

Figure 3 shows the basic situation of 714 COVID-19 patients in Dongxihu Fangcang hospitals. The mean age of the study population was $48.16 \pm 12.44$ years. Out of the 714 patients in total, $319(44.7 \%)$ were men and 395 $(55.3 \%)$ were women (Figure 3A). The average length of the patient's stay in the Fangcang shelter hospital was 16.08 $(\mathrm{SD} \pm 5.13)$ days. Some COVID-19 patients suffer from chronic diseases, mainly including diabetes $(28.85 \%)$, cardiovascular diseases (25.21\%), hypertension (20.59\%) and respiratory system disease (17.51\%) (Figure 3B). All 


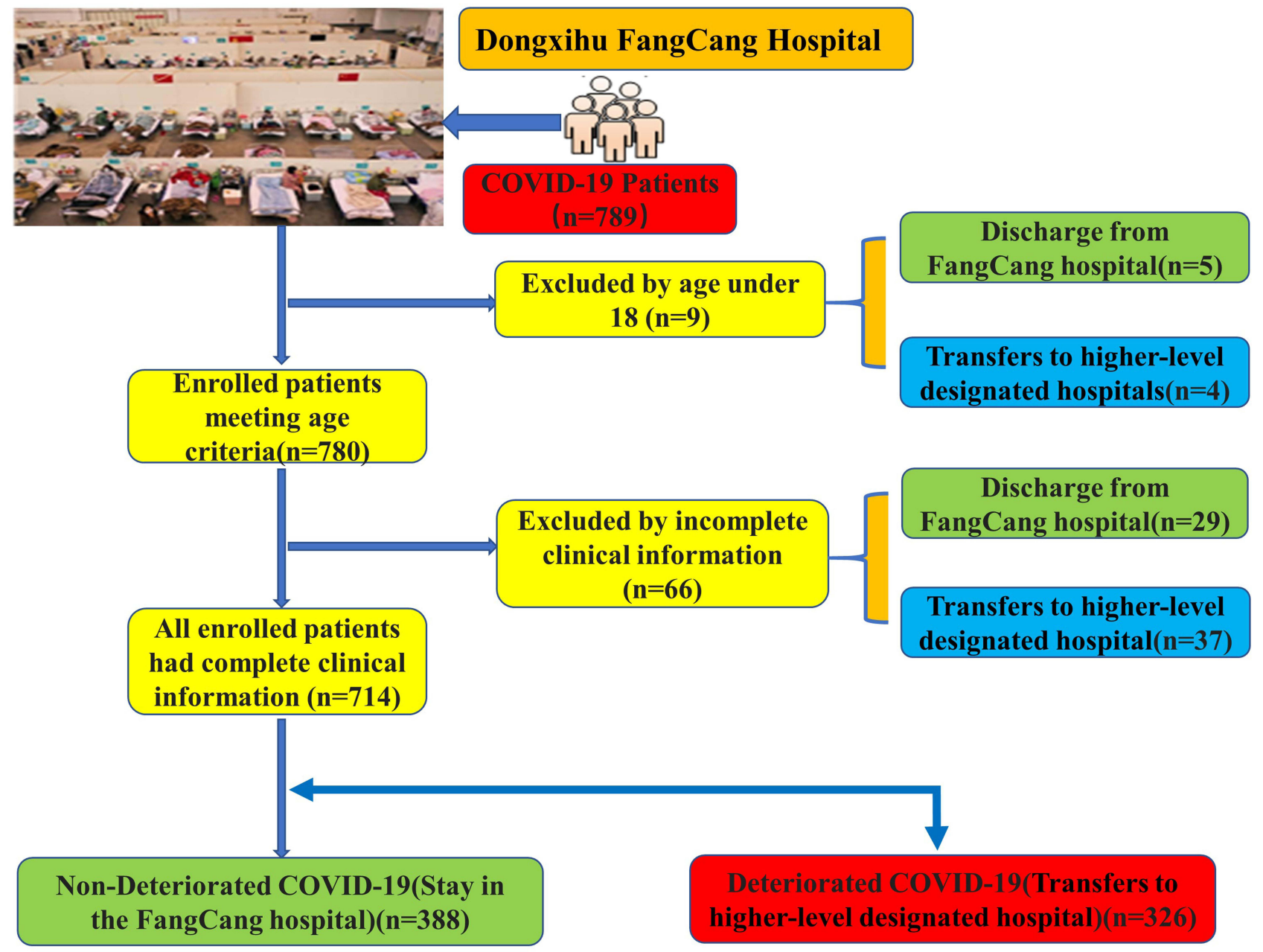

Figure I The flowchart of COVID-19 patients admitted to Fangcang shelter hospital.

patients had a history of living in the pandemic area (Wuhan) in the last month. The most common clinical feature on admission was fever (593 of $714,83.05 \%$ ). It is worth noting that $80(11.20 \%)$ of the 714 patients were asymptomatic from exposure to admission (Figure 3C). In addition, All COVID-19 patients received traditional

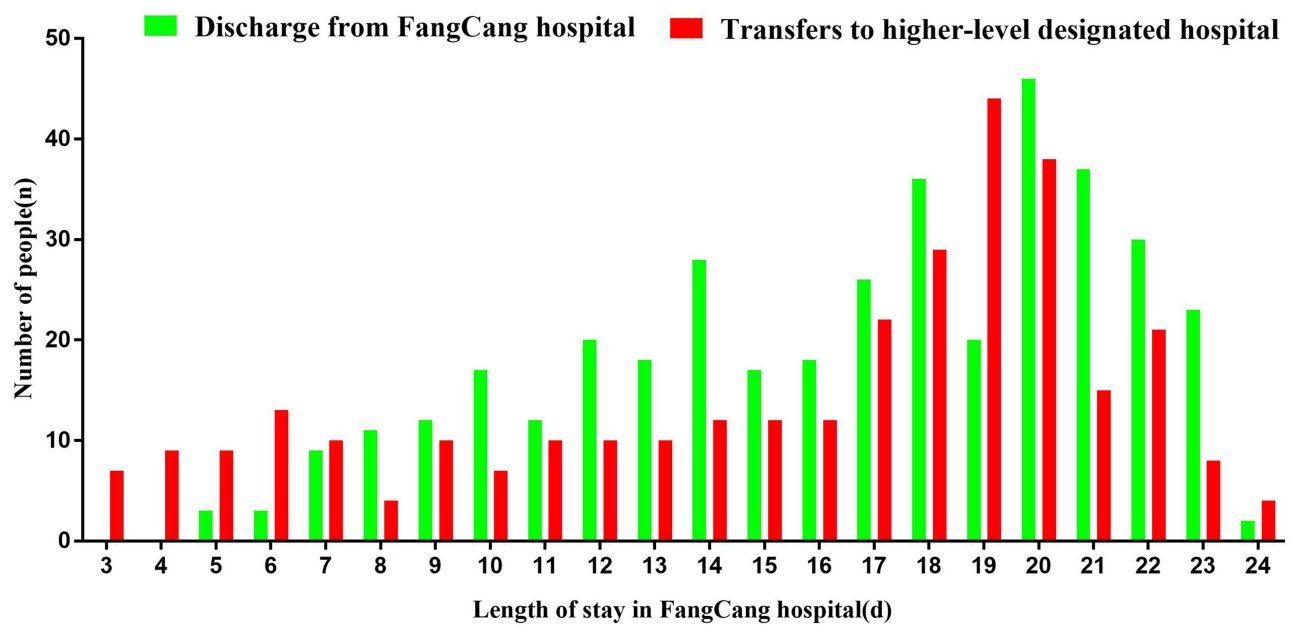

Figure 2 The discharge or transfer time of each patient in the Fangcang shelter hospital. 

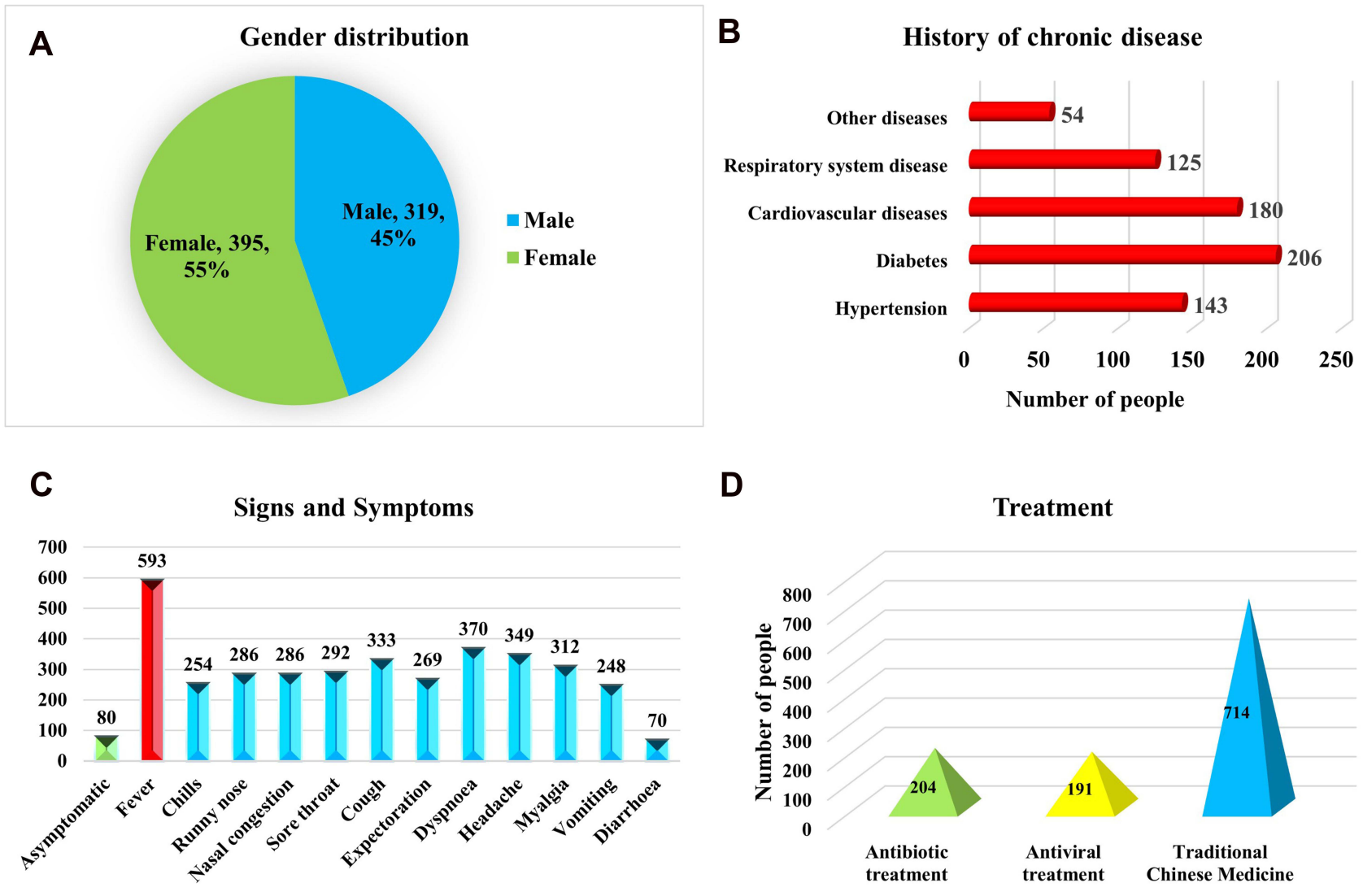

D

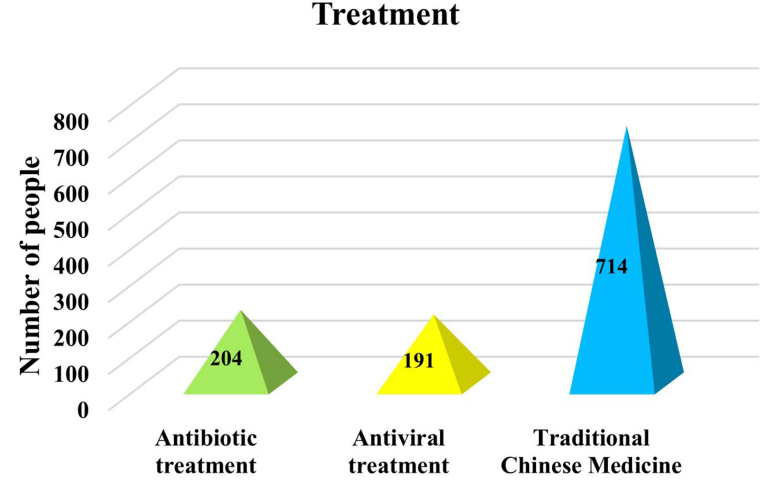

Figure 3 Basic situation of 714 COVID-19 patients in Dongxihu Fangcang hospitals. (A) Gender distribution of COVID-19 patients; (B) Chronic medical illness; (C) Signs and symptoms on admission; (D) Treatment of COVID-19 patients.

Chinese medicine treatment, and some patients also received antibiotic or antiviral treatment (Figure 3D).

\section{Factors Associated with Non-Severe to Severe COVID-19 in Fangcang Hospital}

We compared the clinical characteristics of the deteriorated and non-deteriorated patient groups (Table 3). Further, we performed univariate and multivariate logistics regression analysis on the two groups of patients. Univariate logistics regression analysis showed that age, gender, hypertension, diabetes, cardiovascular disease, respiratory system disease, asymptomatic, fever, chills, runny nose, nasal congestion, sore throat, cough, expectoration, dyspnoea, headache, myalgia, vomiting, CT ground-glass opacity and CT bilateral pulmonary infiltration were related to the deterioration of COVID-19 patients. Whereas, Multivariate logistic regression analysis showed that gender (OR: 6.321; 95\% CI: 4.063-9.833; $P<0.001$ ), age (OR: 3.235; 95\% CI: 2.245-4.661; $P<0.001$ ), diabetes (OR: 2.285; 95\% CI: 1.269-4.112;
$P=0.006)$, respiratory system disease (OR: $2.258 ; 95 \%$ CI: $1.170-4.359 ; P=0.015$ ), fever (OR: 3.053; 95\% CI: 1.691-5.512; $P<0.001$ ), dyspnea (OR: 5.188; 95\% CI: 3.413-7.887; $P<0.001$ ), and nasal congestion (OR: 1.794; 95\% CI: $1.098-2.931 ; P=0.020)$ were risk factors associated with deterioration in cases with COVID-19 patients, and asymptomatic (OR: 0.058; 95\% CI: 0.022-0.155; $P<0.001)$ was the protective factor for deterioration of COVID-19 patients (Figure 4).

\section{Discussion}

A total of 714 patients with mild to moderate COVID-19 treated in Wuhan Dongxihu Fangcang Hospital were included in our retrospective study. Among them, there are more female $(55.3 \%)$ patients than males $(44.7 \%)$. Some COVID-19 patients suffer from chronic diseases such as diabetes (28.85\%), cardiovascular disease (25.21\%), hypertension $(20.59 \%)$ and respiratory disease $(17.51 \%)$. This is similar to the results of the clinical characteristics analysis of COVID-19 patients reported so far. $^{3,4,9}$ The main symptoms of patients include fever, 
dyspnea, cough, headache, etc. The most common clinical feature was fever (593 out of $714,83.05 \%$ ), which was the same as the reported clinical symptoms of COVID-19 hospitalized patients. $^{7,8}$ It is worth noting that 80 $(11.20 \%)$ of the 714 patients were asymptomatic from exposure to admission. In addition, we also found some different characteristics. In our study, no patients died during treatment, and $45.66 \%$ of patients were transferred to designated hospitals due to their worsening conditions. Most patients had mild manifestations and excellent prognoses. Meanwhile, our research shows that gender, age, diabetes, respiratory system disease, fever, dyspnea, and nasal congestion were risk factors for the deterioration of COVID-19 patients, and asymptomatic manifestation was protective factors for deterioration. A retrospective study found that the patient's age, hypertension and heart disease are independent risk factors for the progression of COVID-19 patients in Fangcang shelter hospitals. ${ }^{3}$ In addition, some studies have also found that older age, a history of Wuhan exposure, diarrhea, chronic kidney disease, diabetes, cardiovascular disease, chest CT showing consolidation, lymphopenia, increased myoglobin and increased white blood cell count were COVID-19 risk factors for aggravation of patients. ${ }^{4,10,11}$ These studies have shown that for the elderly and patients with potential comorbidities, more attention and early intervention are needed to avoid the development of severe illness or even death.

We also observed that there were more women $(63.92 \%)$ than men $(36.08 \%)$ in the non-deteriorated patients, and more men (54.91\%) than women (45.09\%) in the deteriorated patients. Our results suggest that elderly men with chronic diseases are more likely to be infected with the COVID-19 virus because these patients have weaker immune functions. Studies have shown that women's reduced susceptibility to viral infections may be attributed to the protection of $\mathrm{X}$ chromosomes and sex hormones, which play an important role in innate immunity and adaptive immunity. ${ }^{12}$ Additionally, patients with mild to moderate COVID-19 without chronic underlying disease are more likely to be cured. This is similar to the results of hospitalized COVID-19 patients. ${ }^{9}$ Deteriorated patients are much older than non-deteriorated patients, which may be related to lower immune response and higher frequency of underlying diseases, which is not conducive to self-limited recovery after viral infection. Therefore, it is not difficult to understand that old age is one of the factors influencing the progression of COVID-
19. Recent studies showed that the degree of disease progression and mortality in elderly COVID-19 patients was also significantly higher than that in younger patients. Therefore, more attention and active treatment should be given to elderly patients in Fangcang hospitals or hospitals.

Many studies have shown that COVID-19 patients with a history of chronic disease are more difficult to cure, and the disease is also more likely to develop into a severe disease or even cause death. ${ }^{13-15}$ Our research showed that diabetes and respiratory system disease were the factors that influenced the transition from non- deteriorated to deteriorated COVID-19 patients. Studies have not found a clear association between diabetes and the serious illness of COVID-19. ${ }^{16}$ However, reports from China and Italy show that elderly COVID-19 patients with chronic diseases including diabetes are more likely to get worse and death. ${ }^{17,18}$ Another study showed that COVID-19 patients with diabetes progress faster, which is not conducive to the prognosis. ${ }^{15}$ Furthermore, studies have shown that COVID19 patients with respiratory system disease were more likely to develop severe illness or death, especially chronic obstructive pulmonary disease (COPD) patients. ${ }^{19}$ The reason may be the changes in the expression of Angiotensinconverting enzyme 2 (ACE2) in the lungs of patients with respiratory system disease. ${ }^{20}$ Current studies have shown that ACE2 is related to the occurrence and development of SARS-CoV ${ }^{21}$ and SARS-CoV-2. ${ }^{22}$ It is worth noting that the number of co-existing symptoms was also correlated with the COVID-19 patients' disease progression. ${ }^{2}$ Our research also showed that fever, dyspnea, and nasal congestion risk factors for the deterioration of COVID-19 patients. When a patient has multiple symptoms, it means that the patient's viral load is very large, which not only severely affects the respiratory system, but also severely affects multiple body systems. Therefore, attention should be paid to symptomatic and supportive treatment. The alleviation of symptoms will not only enhance the patient's confidence in overcoming the disease, but also reduce the patient's discomfort, anxiety and fear.

Studies have shown that the most likely source of asymptomatic infections is close contacts of patients who have been diagnosed or suspected, and family clusters have been presented before. ${ }^{23,24}$ Our research shows that 80 of $714(11.2 \%)$ patients were asymptomatic, while 27 of 714 patients $(7.8 \%)$ remained asymptomatic during the entire follow-up period, with a median duration of 21 days (IQR 18-24). There are no specific results regarding the 
Table 3 Univariate and Multivariate Logistic Regression Analysis of Factors Related to the Deterioration of COVID-19 Patients

\begin{tabular}{|c|c|c|c|c|c|c|c|}
\hline \multirow[t]{2}{*}{ Items } & \multirow[t]{2}{*}{ Variables } & \multirow{2}{*}{$\begin{array}{l}\text { Non- Deteriorated } \\
\text { Patients }(\mathrm{N}=\mathbf{3 8 8})\end{array}$} & \multirow{2}{*}{$\begin{array}{l}\text { Deteriorated } \\
\text { Patients }(\mathrm{N}=326)\end{array}$} & \multicolumn{2}{|c|}{ Univariable OR } & \multicolumn{2}{|c|}{ Multivariable OR } \\
\hline & & & & OR & $95 \% \mathrm{Cl}$ & OR & $95 \% \mathrm{Cl}$ \\
\hline \multirow[t]{3}{*}{ Gender } & & & & & & & \\
\hline & Male & $140(43.89 \%)$ & $179(56.11 \%)$ & 2.157 & 1.597 to $2.194 *$ & 6.321 & 4.063to9.833* \\
\hline & Female & $248(62.78 \%)$ & |47(37.22\%) & 1 & & 1 & \\
\hline \multirow[t]{3}{*}{ Age (years) } & & & & & & & \\
\hline & $\geq 50 y$ & $205(57.75 \%)$ & $150(42.25 \%)$ & 2.688 & 1.984 to $3.642 *$ & 3.235 & 2.245 to $4.66 \mathrm{I} *$ \\
\hline & $<50 y$ & $183(50.97 \%)$ & I76(49.03\%) & 1 & & 1 & \\
\hline \multirow[t]{3}{*}{ Hypertension } & & & & & & & \\
\hline & Yes & $63(44.06 \%)$ & $80(55.94 \%)$ & 1.678 & 1.160to $2.427 *$ & & \\
\hline & No & $325(56.92 \%)$ & $246(43.08 \%)$ & 1 & & & \\
\hline \multirow[t]{3}{*}{ Diabetes } & & & & & & & \\
\hline & Yes & 77 (37.38\%) & $129(62.62 \%)$ & 2.645 & I.894to3.693* & 2.285 & 1.269to4.II2* \\
\hline & No & $3 \mid I(6 \mid .22 \%)$ & 197(38.78\%) & 1 & & I & \\
\hline \multirow[t]{3}{*}{ Cardiovascular } & & & & & & & \\
\hline & Yes & $72(40.00 \%)$ & $108(60.00 \%)$ & 2.174 & I.54I to3.069* & & \\
\hline & No & $316(59.18 \%)$ & $218(40.82 \%)$ & 1 & & & \\
\hline \multirow[t]{3}{*}{$\begin{array}{l}\text { Respiratory system } \\
\text { disease }\end{array}$} & & & & & & & \\
\hline & Yes & $53(42.40 \%)$ & $72(57.60 \%)$ & 1.792 & 1.213 to $2.647^{*}$ & 2.258 & I.170to $4.359 *$ \\
\hline & No & $335(56.88 \%)$ & $254(43.12 \%)$ & 1 & & 1 & \\
\hline \multirow[t]{3}{*}{ Asymptomatic } & & & & & & & \\
\hline & Yes & 59 (73.75\%) & $21(26.25 \%)$ & 0.380 & $0.176 \mathrm{to} 0.819 *$ & 0.058 & 0.022 to $0.155^{*}$ \\
\hline & No & $329(51.89 \%)$ & $305(48.11 \%)$ & 1 & & 1 & \\
\hline \multirow[t]{3}{*}{ Fever } & & & & & & & \\
\hline & Yes & $294(49.58 \%)$ & $299(50.42 \%)$ & 3.541 & 2.24 I to5.593* & 3.053 & I.69I to $5.512^{*}$ \\
\hline & No & $94(77.69 \%)$ & $27(22.31 \%)$ & 1 & & 1 & \\
\hline \multirow[t]{3}{*}{ Chills } & & & & & & & \\
\hline & Yes & $100(39.37 \%)$ & $154(60.63 \%)$ & 2.579 & I.882to3.532* & & \\
\hline & No & $288(62.61 \%)$ & $172(37.39 \%)$ & 1 & & & \\
\hline \multirow[t]{3}{*}{ Runny nose } & & & & & & & \\
\hline & Yes & II 5 (40.2I\%) & I7I (59.79\%) & 2.619 & 1.925to3.563* & & \\
\hline & No & $273(63.79 \%)$ & $155(36.21 \%)$ & 1 & & & \\
\hline \multirow[t]{3}{*}{ Nasal congestion } & & & & & & & \\
\hline & Yes & III(38.8I\%) & $175(61.19 \%)$ & 2.892 & 2.122 to $3.942 *$ & 1.794 & I.098to2.93I* \\
\hline & No & $277(64.72 \%)$ & $|5|(35.28 \%)$ & 1 & & 1 & \\
\hline \multirow[t]{3}{*}{ Sore throat } & & & & & & & \\
\hline & Yes & $135(46.23 \%)$ & I57(53.77\%) & 1.741 & 1.288to2.353* & & \\
\hline & No & $153(47.52 \%)$ & $169(52.48 \%)$ & 1 & & & \\
\hline \multirow[t]{3}{*}{ Cough } & & & & & & & \\
\hline & Yes & $158(47.45 \%)$ & $175(52.55 \%)$ & 1.687 & I.253to $2.27 \mathrm{I} *$ & & \\
\hline & No & $230(60.37 \%)$ & $15 \mathrm{I}(39.63 \%)$ & 1 & & & \\
\hline
\end{tabular}


Table 3 (Continued).

\begin{tabular}{|c|c|c|c|c|c|c|c|}
\hline \multirow[t]{2}{*}{ Items } & \multirow[t]{2}{*}{ Variables } & \multirow{2}{*}{$\begin{array}{l}\text { Non- Deteriorated } \\
\text { Patients }(\mathrm{N}=\mathbf{3 8 8})\end{array}$} & \multirow{2}{*}{$\begin{array}{l}\text { Deteriorated } \\
\text { Patients }(\mathrm{N}=326)\end{array}$} & \multicolumn{2}{|c|}{ Univariable OR } & \multicolumn{2}{|c|}{ Multivariable OR } \\
\hline & & & & OR & $95 \% \mathrm{Cl}$ & OR & $95 \% \mathrm{Cl}$ \\
\hline \multirow[t]{3}{*}{ Expectoration } & & & & & & & \\
\hline & Yes & $123(45.72 \%)$ & | $4654.28 \%)$ & 1.748 & 1.287 to $2.372^{*}$ & & \\
\hline & No & $265(59.55 \%)$ & $180(40.45 \%)$ & I & & & \\
\hline \multirow[t]{3}{*}{ Dyspnoea } & & & & & & & \\
\hline & Yes & $152(41.08 \%)$ & $218(58.92 \%)$ & 3.134 & 2.304 to $4.264^{*}$ & 5.188 & 3.4I3to7.887* \\
\hline & No & $236(68.60 \%)$ & $108(31.40 \%)$ & I & & I & \\
\hline \multirow[t]{3}{*}{ Headache } & & & & & & & \\
\hline & Yes & 148 (42.41\%) & $20 \mathrm{I}(57.59 \%)$ & 2.608 & 1.926 to $3.530 *$ & & \\
\hline & No & $240(65.75 \%)$ & $125(34.25 \%)$ & I & & & \\
\hline \multirow[t]{3}{*}{ Myalgia } & & & & & & & \\
\hline & Yes & $126(40.38 \%)$ & 186 (59.62\%) & 2.763 & 2.036 to $3.749 *$ & & \\
\hline & No & $262(65.17 \%)$ & I40(34.83\%) & I & & & \\
\hline \multirow[t]{3}{*}{ Vomiting } & & & & & & & \\
\hline & Yes & 119 (47.98\%) & $129(52.02 \%)$ & 1.480 & $1.086 \mathrm{to} 2.017^{*}$ & & \\
\hline & No & $269(57.73 \%)$ & $197(42.27 \%)$ & I & & & \\
\hline \multirow{3}{*}{$\begin{array}{l}\text { CT ground-glass } \\
\text { opacity }\end{array}$} & & & & & & & \\
\hline & Yes & $197(42.46 \%)$ & $267(57.54 \%)$ & 4.388 & 3.107 to6.196* & & \\
\hline & No & $191(76.40 \%)$ & $59(23.60 \%)$ & I & & & \\
\hline \multirow[t]{3}{*}{$\begin{array}{l}\text { CT bilateral } \\
\text { pulmonary infiltration }\end{array}$} & & & & & & & \\
\hline & Yes & $179(4 \mid .53 \%)$ & $252(58.47 \%)$ & 3.976 & 2.867 to $5.515^{*}$ & & \\
\hline & No & 209(73.85\%) & $74(26.15 \%)$ & I & & & \\
\hline
\end{tabular}

Note: *For $P<0.05$ at univariate and multivariate analysis.

incidence of asymptomatic infections. However, large sample studies show that the asymptomatic ratio of SARSCOV-2 infection in China is about $16 \%,{ }^{17}$ while the asymptomatic ratio of SARS-COV-2 infection in the United States exceeds $50 \%{ }^{25}$ Meanwhile, our research found that asymptomatic infection is a protective factor for the deterioration of COVID-19 patients. Current research believes that lower levels of ACE2 and weaker binding capacity to SARS-CoV-2 should be the main factors leading to asymptomatic infections without any clinical manifestations. ${ }^{24,26}$ In addition, it has been reported that SARS-CoV-2 invasion caused only a specific mild immune response in asymptomatic patients. ${ }^{26}$ Therefore, these may be the reasons why the condition of asymptomatic patients infected by SARS$\mathrm{CoV}-2$ is not easily deteriorated. Since our research on SARS-CoV-2 is still limited, the specific causes of asymptomatic occurrence need further research. At present, the limited understanding of asymptomatic infections of COVID-19 is easily overlooked. Therefore, timely isolation of asymptomatic infections is of great significance to the prevention and control of COVID- 19 .

\section{Conclusion}

Our study is a single-center study with certain limitations. The 13 Fangcang hospitals in Wuhan have treated more than 12,000 COVID-19 patients. We only conducted a statistical analysis of 714 of them, and the results may be subject to certain deviations. Non-deteriorated patients and deteriorated patients have different clinical characteristics. Asymptomatic infections account for only a small percentage of COVID-19 patients, but they may be a potential source of infection. In the future, more samples will need to be included for clinical analysis to better understand the clinical characteristics of patients with mild to moderate COVID-19 and provide scientific reference for clinical treatment and prognosis. 


\section{Forest plot}

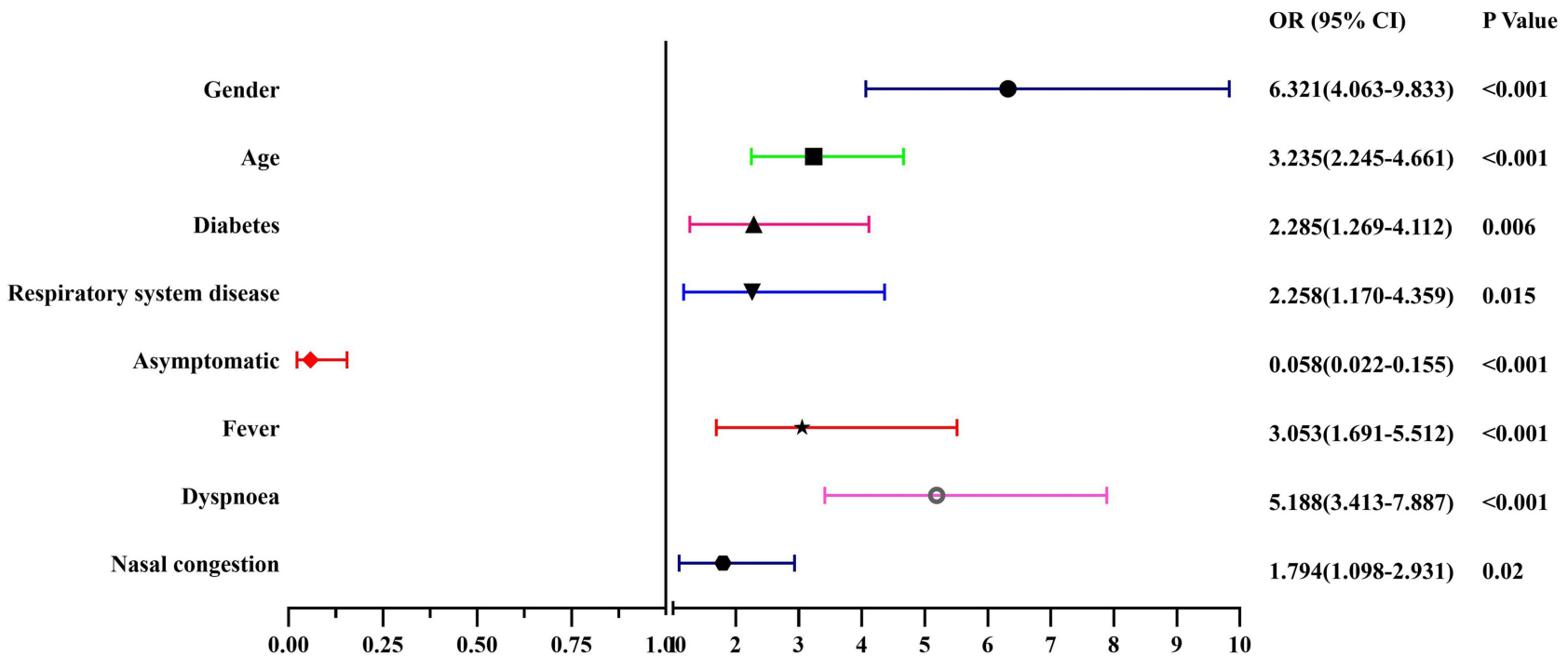

Figure 4 Forest plot of factors related to the deterioration of COVID-19 patients.

\section{Acknowledgments}

We would like to thank all the patients included in this study.

\section{Funding}

This study was supported by the Ningxia Natural Science Foundation (2020AAC02003) and Ningxia Medical University (XE202002).

\section{Disclosure}

All authors declare that there is no conflict of interest.

\section{References}

1. Lu H, Stratton CW, Tang YW. Outbreak of pneumonia of unknown etiology in Wuhan, China: the mystery and the miracle. $J$ Med Virol. 2020;92(4):401-402. doi:10.1002/jmv.25678

2. Zhang JF, Liu J, Ma HN, et al. RT-PCR combined with CT examination in the diagnosis and prognosis evaluation of COVID-19 patients in Fangcang Hospital: a case series. $J$ Multidiscip Healthc. 2021;14:145-149. doi:10.2147/JMDH.S293601

3. Lv Z, Lv S. Clinical characteristics and analysis of risk factors for disease progression of COVID-19: a retrospective Cohort Study. Int J Biol Sci. 2021;17(1):1-7. doi:10.7150/ijbs.50654

4. Wang X, Fang J, Zhu Y, et al. Clinical characteristics of non-critically ill patients with novel coronavirus infection (COVID-19) in a Fangcang Hospital. Clin Microbiol Infect. 2020;26(8):1063-1068. doi:10.1016/j.cmi.2020.03.032

5. Chen C, Zhao B. Makeshift hospitals for COVID-19 patients: where health-care workers and patients need sufficient ventilation for more protection. $J$ Hosp Infect. 2020;105(1):98-99. doi:10.1016/j. jhin.2020.03.008
6. Guan WJ, Ni ZY, Hu Y, et al. Clinical characteristics of coronavirus disease 2019 in China. $N$ Engl J Med. 2020;382(18):1708-1720. doi:10.1056/NEJMoa2002032

7. Yi P, Yang X, Ding C, et al. Risk factors and clinical features of deterioration in COVID-19 patients in Zhejiang, China: a single-centre, retrospective study. BMC Infect Dis. 2020;20(1):943. doi:10.1186/s12879-020-05682-4

8. Wang D, Hu B, Hu C, et al. Clinical characteristics of 138 hospitalized patients with 2019 novel coronavirus-infected pneumonia in Wuhan, China. JAMA. 2020;323(11):1061-1069. doi:10.1001/jama.2020.1585

9. Chen N, Zhou M, Dong X, et al. Epidemiological and clinical characteristics of 99 cases of 2019 novel coronavirus pneumonia in Wuhan, China: a descriptive study. Lancet. 2020;395 (10223):507-513. doi:10.1016/S0140-6736(20)30211-7

10. He F, Luo Q, Lei M, et al. Risk factors for severe cases of COVID-19: a retrospective cohort study. Aging. 2020;12 (15):15730-15740. doi:10.18632/aging.103803

11. Tabata S, Imai K, Kawano S, et al. Clinical characteristics of COVID-19 in 104 people with SARS-CoV-2 infection on the diamond princess cruise ship: a retrospective analysis. Lancet Infect Dis. 2020;20(9):1043-1050. doi:10.1016/S1473-3099(20)30482-5

12. Jaillon S, Berthenet K, Garlanda C. Sexual dimorphism in innate immunity. Clin Rev Allergy Immunol. 2019;56(3):308-321. doi:10.1007/s12016-017-8648-x

13. Li X, Wang L, Yan S, et al. Clinical characteristics of 25 death cases with COVID-19: a retrospective review of medical records in a single medical center, Wuhan, China. Int J Infect Dis. 2020;94:128-132. doi:10.1016/j.ijid.2020.03.053

14. Zheng F, Tang W, Li H, Huang YX, Xie YL, Zhou ZG. Clinical characteristics of 161 cases of corona virus disease 2019 (COVID-19) in Changsha. Eur Rev Med Pharmacol Sci. 2020;24 (6):3404-3410.

15. Guo W, Li M, Dong Y, et al. Diabetes is a risk factor for the progression and prognosis of COVID-19. Diabetes Metab Res Rev. 2020;36:e3319.

16. Lippi G, Plebani M. Laboratory abnormalities in patients with COVID-2019 infection. Clin Chem Lab Med. 2020;58 (7):1131-1134. doi:10.1515/cclm-2020-0198 
17. Wu Z, McGoogan JM. Characteristics of and important lessons from the Coronavirus Disease 2019 (COVID-19) outbreak in China: summary of a report of 72314 cases from the chinese center for disease control and prevention. JAMA. 2020;323(13):1239-1242. doi:10.1001/jama.2020.2648

18. Onder G, Rezza G, Brusaferro S. Case-fatality rate and characteristics of patients dying in relation to COVID-19 in Italy. JAMA. 2020;323 (18):1775-1776.

19. Leung JM, Niikura M, Yang CWT, Sin DD. COVID-19 and COPD. Eur Respir J. 2020;56(2). doi:10.1183/13993003.02108-2020

20. Higham A, Mathioudakis A, Vestbo J, Singh D. COVID-19 and COPD: a narrative review of the basic science and clinical outcomes. Eur Respir Rev. 2020;29(158):200199. doi:10.1183/ 16000617.0199-2020

21. Letko M, Marzi A, Munster V. Functional assessment of cell entry and receptor usage for SARS-CoV-2 and other lineage B betacoronaviruses. Nat Microbiol. 2020;5(4):562-569. doi:10.1038/ s41564-020-0688-y
22. Li W, Moore MJ, Vasilieva N, et al. Angiotensin-converting enzyme 2 is a functional receptor for the SARS coronavirus. Nature. 2003;426(6965):450-454. doi:10.1038/nature02145

23. Yu P, Zhu J, Zhang Z, Han Y, Familial A. Cluster of infection associated with the 2019 novel coronavirus indicating possible person-to-person transmission during the incubation period. $J$ Infect Dis. 2020;221(11):1757-1761. doi:10.1093/infdis/jiaa077

24. Gao Z, Xu Y, Sun C, et al. A systematic review of asymptomatic infections with COVID-19. J Microbiol Immunol Infect. 2021;54 (1):12-16. doi:10.1016/j.jmii.2020.05.001

25. Baggett TP, Keyes H, Sporn N, et al. Prevalence of SARS-CoV-2 infection in residents of a large homeless shelter in Boston. JAMA. 2020;323(21):2191-2192. doi:10.1001/jama.2020.6887

26. Hu ZB, Ci C. Screening and management of asymptomatic infection of corona virus disease 2019 (COVID-19). Chin J Prev Med. 2020;54:E025.

\section{Publish your work in this journal}

Therapeutics and Clinical Risk Management is an international, peerreviewed journal of clinical therapeutics and risk management, focusing on concise rapid reporting of clinical studies in all therapeutic areas, outcomes, safety, and programs for the effective, safe, and sustained use of medicines. This journal is indexed on PubMed Central, CAS,
EMBase, Scopus and the Elsevier Bibliographic databases. The manuscript management system is completely online and includes a very quick and fair peer-review system, which is all easy to use. Visit http://www.dovepress.com/testimonials.php to read real quotes from published authors. 